IZA DP No. 7857

Social Preferences and Lying Aversion in Children

Valeria Maggian

Marie Claire Villeval

December 2013

Forschungsinstitut zur Zukunft der Arbeit Institute for the Study of Labor 


\title{
Social Preferences and Lying Aversion in Children
}

\author{
Valeria Maggian \\ University of Milano-Bicocca
}

Marie Claire Villeval

Université de Lyon, CNRS, GATE

and IZA

\section{Discussion Paper No. 7857 \\ December 2013}

\author{
IZA \\ P.O. Box 7240 \\ 53072 Bonn \\ Germany \\ Phone: +49-228-3894-0 \\ Fax: +49-228-3894-180 \\ E-mail: iza@iza.org
}

Any opinions expressed here are those of the author(s) and not those of IZA. Research published in this series may include views on policy, but the institute itself takes no institutional policy positions. The IZA research network is committed to the IZA Guiding Principles of Research Integrity.

The Institute for the Study of Labor (IZA) in Bonn is a local and virtual international research center and a place of communication between science, politics and business. IZA is an independent nonprofit organization supported by Deutsche Post Foundation. The center is associated with the University of Bonn and offers a stimulating research environment through its international network, workshops and conferences, data service, project support, research visits and doctoral program. IZA engages in (i) original and internationally competitive research in all fields of labor economics, (ii) development of policy concepts, and (iii) dissemination of research results and concepts to the interested public.

IZA Discussion Papers often represent preliminary work and are circulated to encourage discussion. Citation of such a paper should account for its provisional character. A revised version may be available directly from the author. 


\section{ABSTRACT}

\section{Social Preferences and Lying Aversion in Children}

While previous research has shown that social preferences develop in childhood, we study whether this development is accompanied by reduced use of deception when lies would harm others, and increased use of deception to benefit others. In a sample of children aged between 7 and 14, we find strong aversion to lying at all ages. Lying is driven mainly by selfish motives and envy. Children with stronger social preferences are less prone to deception, even when lying would benefit others at no monetary cost. Older children lie less than younger children and require more self-justification to lie.

JEL Classification: C91, D03, D63

Keywords: lie aversion, deception, social preferences, children, experiment

Corresponding author:

Marie Claire Villeval

GATE (Groupe d'Analyse et de Théorie Economique Lyon St Etienne)

CNRS - University of Lyon

93 Chemin des Mouilles

69130 Ecully

France

E-mail: villeval@gate.cnrs.fr

\footnotetext{
* This research has been supported by a grant from the French National Research Agency (ANR, EMCO program, HEIDI grant) and was performed within the framework of the LABEX CORTEX (ANR11-LABX-0042) of Université de Lyon, within the program "Investissements d'Avenir" (ANR-11-IDEX007) operated by the French National Research Agency (ANR). We thank participants at the ESA world meeting in New-York, the Toulouse-Lyon BEE workshop in Lyon, the Florence Workshop on Behavioral and Experimental Economics, the workshop on Understanding employees' dishonesty behavior in the workplace in Dijon, and seminar participants at the University of Paris I for useful comments.
} 


\section{INTRODUCTION}

The ideal figure of homo oeconomicus has been challenged from two perspectives. First, extensive research has established that individuals make conscious decisions revealing other-regarding preferences towards strangers (Heinrich et al. 2001, Fehr and Fischbacher 2003, Dawes et al. 2007, Tricomi et al. 2010), making cooperation achievable (Ostrom 1990, Fehr and Fischbacher 2002). Second, contrary to the notion that individuals rationally violate moral norms provided this brings marginal net benefits, recent research provides evidence that people value honesty (Charness and Dufwenberg 2006, Lundquist $e t$ al. 2009, Fischbacher and Föllmi-Heusi 2013, Lopez-Perez and Spiegelman 2013; Pruckner and Sausgruber 2013, Gibson, Tanner and Wagner 2013). Honesty enhances mutual trust, conditions the efficacy of policies (Nyberg 1997, Hilbig and Zettler 2009), and is fundamental for preserving human dignity, according to the Kantian imperative (Kant 1998). However, pursuing a moral conduct may sometimes conflict with the desire to improve others' welfare. As shown by Gneezy (2005), Hurkens and Kartik (2009) and Erat and Gneezy (2012), the decision to lie is not only sensitive to the liar's incentives but also to the consequences of the lie on others' well-being. When the pursuit of otherregarding preferences implies lying, individuals face a moral dilemma. 
Analyzing such a dilemma is extremely relevant in childhood, a crucial phase in the process of development of both other-regarding preferences and moral reasoning ${ }^{1}$. Other-regarding preferences are found to develop as children age (Benenson, Pascoe and Radmore 2007), with children at age 7-8 becoming less selfish and more inequality averse than 3-4 years old children (Fehr, Bernhard and Rockenbach 2008, Blake and Rand 2010). Later on, egalitarianism becomes less frequent and efficiency concerns more prominent (Fehr, Glätzle-Rützler and Sutter 2013); moreover, females are more frequently classified as egalitarian than males (Martinsson et al. 2011), even if the disutility from having less than others becomes less important with age for both genders.

The development of moral reasoning has been a focus of investigation in psychology $^{2}$ (Bussey 1999, Talwar and Crossman 2011), but rarely in economics (one exception is Bucciol and Piovesan 2011). ${ }^{3}$ Lewis, Stanger and Sullivan (1989) and Chandler, Fritz and Hala (1989) have shown that children's understanding of the opportunity to not tell the truth in order to pursue personal interest or to avoid punishment, emerges as early as three years of age. Deceitful behavior evolves during school years as children develop executive control

\footnotetext{
1 Experiments with children are becoming more frequent in economics. While initial analysis was mostly focused on the development of other-regarding preferences (Harbaugh and Krause 2000, Fehr, Bernhard and Rockenbach 2008, Almas et al. 2010, Martinsson et al. 2011, Fehr, Glätzle-Rützler and Sutter 2013) and trust (Harbaugh et al. 2003, Sutter and Kocher 2007 ) in children, recent research also investigates the emergence of a gender gap in competiveness (Gneezy and Rustichini 2004, Sutter and Rützler 2010, Dreber, von Essen and Ranehill 2011) and risk and ambiguity attitudes (Harbaugh et al. 2002, Sutter et al. 2013).

2 Piaget (1965) is among the first psychologists suggesting a theory of moral development.

3 Bucciol and Piovesan (2011) study honesty in children between the age of 5 and 15 . Children are asked to toss a coin and report the outcome. Evidence of cheating is found when lying is profitable and cannot be detected.
} 
functions and theory of mind (Talwar, Gordon and Lee 2007, Talwar and Lee 2008), and the ability to infer correctly which social and moral norms may be violated when lying (Xu et al. 2010; Bussey 1992). However, most studies investigate children's understanding of social rules (Talwar, Murphy and Lee 2007, Broomfield, Robinson and Robinson 2002) but disregard how their decision to lie is affected by its economic consequences on others' welfare. A priori, there are two main plausible developmental pathways. On the one hand, since unconditional lie-aversion has been observed in adults, we expect the internalization of the value of honesty to be already present in childhood. On the other hand, since adults are sensitive to the consequences of their lies on other's payoffs we might expect that older children, who are more likely to care about other's welfare as they age, become also more likely to lie to benefit others.

In this paper we analyze whether children's deceitful behavior depends on their other-regarding preferences in presence of economic incentives. Collecting data both on deceptive behavior and on social preferences in a natural environment is, however, extremely difficult. Using instead survey data with children on this topic is unlikely to provide reliable information. For that reason, we conducted a controlled experiment in classrooms. Our experiment involved 637 Italian children (326 females and 311 males) in three age groups, from middle childhood (7-8 and 9-10 years old) to early adolescence (11 and 14 years old). We gave children the opportunity to lie in order to achieve their preferred outcome, 
making them conscious that their choice would influence both their own payoff and their partner's welfare. We study whether having a preference for a particular allocation of resources (i.e. an other-regarding or a self-regarding allocation) affects children's willingness to lie to achieve it, according to their age and gender. ${ }^{4}$

Precisely, our experiment consists of a modified version of the dictator game that was played in two stages. In the first stage each child had to choose between two options for the allocation of resources between himself and an anonymous classmate. The chosen option allows us to measure each child's social preferences. In the second stage a random device selected one of the two same options. Each child was then asked to report the option that had been randomly drawn. If this option did not correspond to his preferred one, the child had the possibility to lie by reporting his preferred option instead of the observed one. Both decisions were made in private in a separate room. This design allows us to examine children's individual lying behavior conditioned on their preferences over allocations. We implemented three different treatments with different allocation options to study various social preferences (namely, altruism, inequity aversion, efficiency concerns).

4 Dreber and Johannesson (2008) report gender differences in deception, which however disappear with larger stakes (Childs 2012). We want to investigate whether the greater aversion to lying of females with respect to males emerges in childhood, when the consequences of lies affect both the liar and the receiver of the lie. 
We find that a large fraction of children is reluctant to tell lies, even when the lie could benefit the receiver without entailing a personal monetary cost. We also show that lying behavior follows a hump-shaped time-path along age groups, with the 9-10 years old children more likely to lie than the oldest ones. While otherregarding preferences develop with age, lying behavior does not develop along the same path. Older children who become more concerned about others' welfare lie less than younger ones. Interestingly, we find that older children lie more if they can manipulate the truth at their advantage without altering their self-image. Our results suggest that older children need self-justification to deceive. Male children are more likely to tell lies that hurt others compared to female children, but this gender gap tends to disappear when aging.

Our analysis also reveals that ethical preferences are correlated with social preferences. The frequency of lie telling is much higher for children having a preference for an allocation of resources that reveals selfishness or envy, independently on their age, than for socially-oriented children. For example, when the choice in the first stage of the experiment was between a selfish and an equal allocation of resources, children who exhibited inequity aversion are less likely to lie in the second stage (to implement an equal sharing) compared to children who made an initial selfish choice. Similarly, altruistic children never lie. Finally, when the choice was between an efficient and an equal allocation of resources, children who exhibited efficiency concerns are less prone to lie to increase the recipients' payoff 
than envious children who lie to decrease the other's payoff without increasing their own payoff. Since we find more social preferences in older children, this explains that on average, the frequency of lies is lower among older children.

The remainder of our study proceeds as follows. The next section describes our experimental design. Section III develops the experimental results. Section IV discusses these results and concludes.

\section{EXPERIMENTAL METHOD}

In order to study whether there is a correlation between children's other-regarding preferences and ethical preferences against lying, we designed a two-stage computerized experiment using the z-Tree software (Fischbacher 2007). ${ }^{5}$ Precisely, we implemented a simplified version of the Dictator game. Since our sample was composed by children it was important to design the simplest possible game allowing us to analyze lying behavior conditioned on children's other regarding preferences.

\footnotetext{
${ }^{5}$ We think that asking children to use a computer was not an issue. Indeed, according to recent research, the average Italian child from age 2 to 11 spends 22 hours a month on the computer and children from age 2 to 5 are more likely to be able to use a computer mouse and play a computer game than to tie their own shoelaces (Bricolo et al. 2007; Heussner 2010). Moreover, the experimenter stood nearby the decision room in case the child needed help. No child has encountered any problem with the computer.
} 


\section{A Participants and procedures}

A total of 637 participants aged between 7 and 14 years took part in this experiment. ${ }^{6}$ We run the experiment in three schools in Vicenza and Treviso (Italy). The same session logistics was used in all schools. After having planned the experimental sessions with headquarters and teachers we asked the latter to give children's parents the informative material, the consent form and a questionnaire to fill in order to allow their children to participate in the experiment. The questionnaire served us to get demographic information about children. Teachers and headmasters were also aware that they were not allowed to reveal the purpose of the experiment to children and parents, or to provide details about the content of the protocol. ${ }^{7}$ However, parents had the opportunity to contact us for getting clarifications. Only children whose parents have signed the consent form could participate in the experiment; moreover, children were explicitly asked if they wanted to participate.

We used a room that was separated from the classroom to allow each child to make his decisions alone, in private, while the experimenter was waiting outside (see on-line Appendix 1). At the beginning of the sessions, each child was randomly paired with an anonymous classmate. None of the children was

\footnotetext{
${ }^{6}$ In total, our sample consists of 637 children. We contacted 742 parents, and 686 gave their consent ( 92 percent). The size of the final dataset is reduced further because 2 children voluntary decided not to participate and 42 children were missing the day of the experiment. 34 classes in total participated in the experiment, with an average of 19 students per class (S.D. $=3.45$ ).

${ }^{7}$ Similarly, for obvious security reasons, the teachers were present in the classroom during the experiment (not in the decision room), but they agreed not to communicate with the children about the experiment during the session.
} 
informed about the identity of his partner. Instructions were explained to all children in the class but questions were asked and answered privately. ${ }^{8}$ Instructions for the two stages of the experiment were read in a row: in such a way, children had to go to the other room to play the game only once, reducing the possibility of communicating their choices to their peers during the experiment. This procedure also saved time (the average duration of the game was about 50 minutes). ${ }^{9}$ It also required that children's attention remains focused for the entire duration of the instructions. To help children, instructions were briefly explained one more time to each child individually before he entered the decision room.

Each child participated to the two stages but was randomly paid only according to the choice he has made in the first or in the second stage. Children were told which stage was paid only at the end of the experiment. Moreover, they were explained that only the choice made by one of the two members in the pair in the selected stage would be randomly selected for payment. ${ }^{10}$ In the payment phase, the earned tokens were exchanged with prizes: the higher the number of

8 The full set of instructions is available in the Appendix.

9

9 Alternatively, we could have asked children to make their first decision on a sheet of paper in the classroom and then to make their second decision on the computer, one by one, alone, in another room. However, with this alternative procedure, children would have taken their decisions in two different environments: in the classroom, sitting next to their peers, and then in isolation in another room. Our procedure kept the environment constant throughout the game.

10 In the case there was an odd number of children in the class, one child was randomly selected to play the game without a partner (this was not made common knowledge): one of his two decisions was randomly selected for determining the child's payment. 
tokens earned by the child, the more prizes he would receive. ${ }^{11}$ These prizes (consisting of pencils, stickers, and small bracelets) were shown to the children from the beginning of the session. Each type of prize was available in large quantity so that children could not be afraid of a shortage of their preferred items.

\section{B. Timing of decisions}

In the first stage of the experiment, each child was asked to decide how to allocate a certain amount of tokens between himself and an anonymous classmate. Two options were available: one option gave both children the same number of tokens; the alternative, depending on the treatment, assigned the child more or less tokens than his partner. The child's choice indicated his social orientation, as detailed below.

In the second stage, in order to elicit attitudes towards lying, we asked each child to press a button on the computer located in the separate room to make a shape - a sun or a star - appear on the screen (see Figure 1). The child was informed that each shape would appear with one chance out of two. Each shape was associated with one of the two allocation options used in the first stage. It was made clear that the shape appearing was random and independent of their decision in the first stage. The child was instructed to report the shape observed on the

\footnotetext{
11 A picture of the prizes can be found in the on-line Appendix 2. We were not allowed to use monetary prizes but it was clear that the children were really enthusiastic at the prospect of earning these prizes. We implemented a slightly higher exchange rate for payments in the 14 years old group. This approach was taken to ensure that the marginal incentives were comparable across ages.
} 
screen on a reporting sheet (see Figure 1). ${ }^{12}$ Since the corresponding allocation option reported by the child was implemented if the second stage was selected for payment at the end of the session, each child had thus the opportunity to misreport the observed shape to get his preferred allocation option. This was, of course, not made explicit. Similarly, we did not mention in the instructions that it was possible to press the button several times to make the shape corresponding to the favorite option appear. We let the children explore and use or not this opportunity.

\section{[Insert Figure 1 about here]}

In a previous experiment, Lundquist et al. (2009) showed that the distance between a lie and the truth increases the difficulty to tell a lie. Our design allows us to test for this possibility. Although not made explicit, there was indeed a possibility for children to press the button several times until their favorite shape (i.e. allocation option) appears. This procedure allows the child to maintain a positive self-view about being honest (Mazar, Amir and Ariely 2008) while acting dishonestly.

The advantage of our design is that it allows us to measure both deception at the individual level (i.e. reporting a different shape with respect to the first appeared) and its relationship with social preferences, according to the children's age and gender.

\footnotetext{
12 We used this indirect procedure instead of displaying the two allocation options because we thought that it was more neutral. Furthermore, it does not seem to have created any confusion in the children's mind: they understood the correspondence between the shapes and the allocation options.
} 


\section{Treatments}

We vary the treatments to investigate how various types of social preferences affect lying behavior. Each class of the sample was randomly assigned to one of three treatments: Selfishness, Efficiency, or Altruism treatment. One allocation option is common to all three treatments: this option enables an egalitarian distribution of 5 tokens to both the decision-maker and his partner. The equal share was chosen as the benchmark since egalitarianism has been shown to be a major driver of human actions (Dawes et al. 2007). The alternative option creates advantageous or disadvantageous inequality, depending on the treatment.

In the Selfishness treatment, by choosing the $(7,3)$ alternative option, the child increases his own payoff by decreasing that of his partner, revealing selfishness. Choosing $(5,5)$ instead of $(7,3)$ reveals inequality aversion. In the Altruism treatment, instead of choosing $(5,5)$ the child can increase his partner's payoff by choosing the alternative $(3,7)$ option. Since this choice reduces the child's own payoff, it provides evidence of altruism. Finally, in the Efficiency treatment, the child can increase his partner's payoff at no cost to himself by choosing $(5,7)$ instead of the $(5,5)$ option. Efficiency concerns are identified when the percentage of children choosing the $(5,7)$ option is significantly above 50 percent. On the contrary, if more than 50 percent choose the $(5,5)$ option, this may be driven by envy or inequality aversion. 


\section{RESULTS}

We first examine the children's social preferences by age and by gender, before relating them to their deceptive behavior.

\section{A Children's social preferences}

Figure 2 shows the percentage of children choosing the equal sharing $(5,5)$ in the first stage of the experiment, by age and by treatment. In line with previous studies we find that as children age, selfishness becomes less prominent and more children exhibit preferences for efficiency.

In the Selfishness treatment, 48 percent of the $7-8$ year olds, 50 percent of the 9-10 year olds and 63.22 percent of the 11 and 14 year olds choose the egalitarian instead of the selfish option. $\chi^{2}$-tests indicate that children in the oldest age category are significantly more likely to choose the $(5,5)$ instead of the $(7,3)$ option in comparison with both the 7-8 and the 9-10 years old children ( $p=0.079$, $\mathrm{N}=173$, and $p=0.052$ and $\mathrm{N}=162$, respectively). The time path of egalitarian choices is reversed when we consider the Efficiency treatment. A $\chi^{2}$-test confirms at a $5 \%$ significance level that the 11 and 14 year olds are more likely to prefer the $(5,7)$ option than the egalitarian one compared to the $7-8$ year olds $(p=0.035)$, with no difference with the 9-10 year olds ( $p=0.464)$. Indeed, while only 20.27 percent of younger children choose the efficient option, this percentage increases to 30.28 percent for the $9-10$ year olds and to 35.11 percent for the 11 and 14 year 
olds. We interpret this result as an evidence of children becoming more concerned with efficiency as becoming older, since a binomial test strongly rejects the hypothesis that the rate of egalitarian choices corresponds to a random choice in all age groups $(p<0.01)$. In contrast, in the Altruism treatment 96.40 percent of the children prefer equal sharing to the disadvantageous inequality alternative, with no age differences.

\section{[Insert Figure 2 about here]}

Next, we consider the impact of gender on the development of social preferences. In the Selfishness treatment, 64.06 percent of females but only 43.33 percent of males choose to share tokens equally ( $p=0.001, \chi^{2}$-test, $\mathrm{N}=248$ ). Similarly, in the Efficiency treatment, 77.04 percent of females but only 64.79 percent of males choose $(5,5) \quad\left(p=0.025, \chi^{2}\right.$-test, $\left.\mathrm{N}=277\right)$. In the Altruism treatment, 100 percent of females and 91.84 percent of males prefer the egalitarian to the altruistic option ( $p=0.035$, Fisher's exact tests two-tailed, $\mathrm{N}=111$ ). This shows that females are more averse than males to both advantageous and disadvantageous inequality.

However, some of these gender differences reduce as children age. In the Selfishness treatment, 7-8 year old females more frequently choose the egalitarian option than males (59.46 percent of females and 36.84 percent of males). This gender gap increases at age 9-10 $\left(p=0.005, \chi^{2}\right.$-test, $\left.\mathrm{N}=86\right)$ but diminishes strongly at ages 11 and 14 (see Figure 3A). Indeed, the percentage of egalitarian choices 
increases from 33.33 percent at age 9-10 to 58.14 percent at ages 11 and 14 for boys, while for girls it remains almost stable at, respectively, 63.83 and 68.18 percent. In the Efficiency treatment, the gender gap remains approximately constant across ages (Figure 3B) with efficiency concerns increasing for both genders. $^{13}$

\section{[Insert Figures $3 A$ and $3 B$ about here]}

In order to analyze the influence of age, gender and treatments on choices, we report in Table 1 four Probit regressions on pooled data from the Selfishness and Efficiency treatments. ${ }^{14}$ The dependent variable is the binary choice of the egalitarian option $(5,5)$ in the first stage of the game. In model $(1)$, the only independent variable is the selfishness treatment. This variable is a dummy variable that takes value 1 if the child participated in the Selfishness treatment, and 0 if he participated in the Efficiency treatment. In model (2), we add age categories, respectively 7-8 and 9-10 years old. These variables are dummy variables that take value 1 if the child belongs to the defined age category, and 0 otherwise. We also interact each age category with the Selfishness treatment category. Since the omitted category is the 11 and 14 years old children who participated in the Efficiency treatment, the 7-8 and 9-10 variables measure the age trends in choosing the egalitarian choice in the Efficient Treatment. Finally,

\footnotetext{
13 In the Efficiency treatment 26.47 percent of 7-8 years old males and 42.55 percent of 11 and 14 years old males prefer $(5,7)$ to $(5,5)$, while the corresponding percentage for females are 15 and 27.66 percent.

${ }^{14}$ We do not pool the data from the Altruism treatment because there is almost no variation in decisions.
} 
the interaction terms between the Selfishness treatment and each age category measure the differences in the probability of choosing the egalitarian choice between the Selfishness and the Efficiency treatments in each age category versus the difference in the oldest children. In model (3), we include a female dummy variable that takes value 1 if the decision-maker was a female, and 0 otherwise, and an interaction term between the treatment and the gender variables. Finally, model (4) is the most complete model, including all the previous independent variables. Table 1 displays marginal effects.

\section{[Insert Table 1 about here]}

Model (1) in Table 1 shows that children are less likely to choose the egalitarian option when the alternative option allows them to increase their own payoff instead of the other's one. Model (2) shows that this effect is mainly due to younger children. Indeed, the difference between the Selfishness and the Efficiency treatment declines with age, i.e. as children become older, they choose less often the (5-5) option in the Efficiency treatment and more often the (5-5) option in the Selfishness treatment. Model (3) indicates that girls are significantly more prone than boys to share tokens equally, independently on the available alternative option. As shown by the insignificant interaction term between the Selfishness treatment and gender in models (3) and (4), the impact of children's gender on the probability to choose the egalitarian option is the same regardless of the treatment. This analysis is consistent with most of the previous literature on 
the topic (Fehr, Bernhard and Rockenbach 2008, Blake and Rand 2010, Martinsson et al. 2011, Fehr, Glätzle-Rützler and Sutter 2013).

To sum up, our first results can be stated as follows:

Result 1: From 7 to 14 years old children, selfishness diminishes and efficiency concerns increase.

Result 2: Girls are more averse than boys to both advantageous and disadvantageous inequality but the gender gap decreases with age.

\section{B. Lying behavior and social preferences}

Once children have revealed their other regarding preferences, we gave them the opportunity to lie in order to get their favorite allocation option in the second stage of the experiment. In this section we analyze the lying behavior of children, first with respect to age and gender and, next, conditional on their other regarding preferences. We restrict the analysis to the children who did not observe the shape corresponding to their preferred allocation option and thus had an incentive to lie by misreporting the observed shape. Among these 319 children (50 percent of the total sample), only 14.42 percent lied to obtain their favored outcome. ${ }^{15}$ The fact that a large proportion of the participants reported the truth, independently on any preferences over outcomes, is consistent with the notion that most children are lie averse.

\footnotetext{
15 Note that this percentage of liars among children who had an incentive to lie is significantly higher than the percentage of children who observed the shape corresponding to their preferred option but misreported the observed shape (3.42 percent) ( $p<0.001$, normal approximation two sample test of equality of independent proportions, two-tailed, $\mathrm{N}=637$ ). While misreporting could be interpreted as mistakes in the latter case, this cannot be the case in the former case.
} 
Deception, age and gender.-Figure 4 displays the distribution of lies by age group. 12.75 percent of children at age 7-8 lied to get their preferred option. This is roughly 6 percentage points lower than the corresponding fraction of 9-10 year olds (19.20 percent) but this difference is not significant according to a $\chi^{2}$-test. In contrast, 9.78 percent of the 11 and 14 year olds lied. Deceit thus follows a humpshaped path across age groups with 9-10 year olds being significantly more prone to lie than older children $\left(p=0.056, \chi^{2}\right.$-test, $\left.\mathrm{N}=217\right)$. In the following paragraphs we analyze whether lying behavior differs with respect to age categories because of children lying for different reasons at different ages or whether their attitude towards lying is different.

\section{[Insert Figure 4 about here]}

Recent studies have shown that individuals' unethical behavior depends partly on their ability to self-justify their action (Shalvi et al. 2011, Fischabcher and Föllmi-Heusi 2013). In our study, we expect older children, who possess higher deliberate cognitive resources to reason about their actions, to be more likely to need and search justifications for self-serving unethical behavior. To test this hypothesis, we analyze whether observing the shape corresponding to their preferred allocation option after clicking more than once on the computer screen modifies children's ethical perceptions and their subsequent lying behavior.

We find that among the children who have not observed the shape corresponding to their preferred option at first, the likelihood of clicking again to 
make the other shape appear increases from $7-8$ year old (10.78 percent) to 11 and 14 year old children (18.48 percent). Testing the hypothesis that older children are more prone than others to click several times, we find a marginally significant difference at the 10 percent level ( $p=0.064$, two-sample proportion test, onetailed). Next, we observe that while almost 77 percent of the 7-8 year olds misreport the observed shape after clicking only once, this percentage decreases to 66.67 for the 9-10 year olds and to 22.22 for the 11 and 14 years olds (a Fisher's exact test confirms a significant difference in behavior when comparing the older group both with 7-8 and 9-10 years old children $p=0.047$ and $p=0.027$, respectively). Thus, the great majority of older children lie only after having observed their preferred shape when clicking more than once, while younger participants seem not to need such a self-justification for lying. This sheds light on when individuals become concerned about feeling honest while misbehaving.

We also test whether the gender difference in deceitful behavior that has been observed in adults, with males being more likely than females to lie in order to secure a monetary payoff (Dreber and Johanesson 2008), are already present in children. Across all age levels, we find that $16.77 \%$ of boys and $12.10 \%$ of girls lied to get their preferred outcome (however, the difference is not significant; $p=0.246 ; \chi^{2}$-test, two-sided, $\left.\mathrm{N}=319\right)$.

White and black lies in children.-Next, to study whether having a self- or an other-regarding preference affects children's willingness to lie we consider two 
types of lies with respect to their consequences, using the Erat and Gneezy's (2012) categorization of lies. White lies are defined as lies that benefit the other person and black lies as lies that harm the other part. The characterization of white and black lies differs across treatments. In the Selfishness treatment, a black lie -untruthfully reporting the $(7,3)$ preferred allocation option instead of the observed $(5,5)$ option- provides a monetary benefit to the liar while reducing his partner's payoff. In contrast, a white lie -untruthfully reporting the $(5,5)$ preferred option when observing the $(7,3)$ one- equalizes outcomes by diminishing the liar's payoff and increasing the recipient's payoff. In the Efficiency treatment, a black lie -untruthfully reporting $(5,5)$ instead of $(5,7)$ - decreases the other's payoff while providing no monetary benefit to the liar. A white lie -untruthfully reporting $(5,7)$ - increases the recipient's payoff at no monetary cost for the liar. In the Altruism treatment, a black lie -untruthfully reporting $(5,5)$ instead of $(3,7)$ increases the liar's payoff at the expense of his partner, while a white lie untruthfully reporting $(3,7)$ - benefits the partner to the liar's detriment.

In the Selfishness treatment, 20 percent of those who prefer $(7,3)$ but observed the $(5,5)$ option told a black lie, while only 4.84 percent of those who prefer $(5,5)$ to the $(7,3)$ option told a white lie. This difference is significant at the 5 percent level ( $p=0.014$, Fisher's exact test, two-sided, N=127). In the Efficiency treatment, 18.63 percent of the envious children who did not observe their favorite option told a black lie while only 5.13 percent of those who prefer $(5,7)$ lied to 
benefit their partner although such a white lie is free of monetary cost $(p=0.062$, Fisher's exact test, two-sided, $\mathrm{N}=141$ ). In the Altruism treatment, no altruistic child lies whereas 18.75 percent of those who prefer the $(5,5)$ to the $(3,7)$ option tell a black lie. Thus, selfish and envious children are more likely to lie than other-regarding children.

Although children's concern for others' payoffs develops with age, we find no statistical evidence of an evolution in white $v s$. black lie telling behavior with respect to age. Indeed, Figure 5 shows that across all age categories envy and selfishness are more likely to generate lies than other-regarding preferences. Among the children who did not obtain their preferred option, the youngest children lied more for selfish or envy reasons. Indeed, 15.49 percent of them told black lies vs. 6.45 percent who told white lies. The corresponding percentages for the 9-10 year olds were 23.33 percent for black lies and 8.57 percent for white lies. These percentages are significantly different neither from the oldest children (white lies, $p=0.105$, Fisher's exact test, two-sided, $\mathrm{N}=73$; black lies, $p=0.340, \chi^{2}$ test, , $\mathrm{N}=144)$ nor from the youngest ones $(p=0.100$, Fisher's exact test, $\mathrm{N}=66$; $p=0.261, \chi^{2}$-test, $\mathrm{N}=161$, respectively for white and black lies). Finally, 16.67 percent at ages 11 and 14 tell a black lie and not one child is prone to tell a white lie. Thus, we find no statistical evidence of an effect of age on black lie telling behavior.

[Insert Figure 5 about here] 
Finally, regarding the impact of gender when conditioning lying behavior on children's other-regarding preferences, we observe that males are significantly more likely than females to tell black lies. $23.58 \%$ of males but only $14.68 \%$ of females lied when preferring an equal sharing in the Efficiency and Altruism treatments or the $(7,3)$ option in the Selfishness treatment $\left(p=0.097, \chi^{2}\right.$-test, $\mathrm{N}=215$ ). In contrast, females tell more white lies than males but not significantly more $(3.57 \%$ of males and $6.25 \%$ of females tell white lies; $p=0.660$; Fisher's exact test, two-tailed, $\mathrm{N}=104)$. Figure 6 displays the frequency of black lies by gender with respect to age. Boys at age 7-8 seem to be more likely than girls of the same age to tell black lies: $22.86 \%$ of boys lied to get more than their partner or to decrease their partner's payoff, whereas only $8.33 \%$ of girls do so. However, according to a Fisher's exact test this difference is not significant and almost disappears in the oldest children, with $17.86 \%$ of boys and $15.38 \%$ of girls at age 11 and 14 telling black lies.

\section{[Insert Figure 6 about here]}

These results are confirmed by the Probit regressions reported in Table 2 in which the dependent variable is the decision to misreport or not the first observed shape on the screen when having an incentive to misreport it (i.e. among the subjects who actually observed the shape that did not correspond to their preferred allocation option). Five models have been estimated on the pooled data from the three treatments. In model (1), the only independent variable is the other 
regarding choice of the child. This dummy variable takes value 1 if the child expressed other-regarding preferences in the first stage of the game, and 0 if he preferred the self-regarding option (i.e. $(7,3)$ in the Selfishness treatment or $(5,5)$ in the Altruism and Efficiency treatments). In model (2), the independent variables also include the age categories, with the older children as the reference category. Model (3) augments model (2) by including both a female dummy variable and an interaction term between gender and other-regarding preferences to capture a possible specific influence of social preferences on females compared to males. Model (4) adds a justification variable to model (3). This dummy variable takes value 1 if the child obtained a self-justification for lying by observing his preferred shape only after clicking several times on his computer screen. It is equal to 0 if the child did not click several times on his screen to make a different shape appear or, even when doing so, he did not observe his preferred shape. Finally, model (5) is similar to model (4) except that it also includes interaction terms between the justification variable and age categories to test for a possible different need for self-justification across age categories. Table 2 reports the marginal effects of these independent variables.

\section{[Insert Table 2 about here]}

In Table 2, all models confirm that holding other-regarding preferences reduces the children's willingness to misreport the truth. Children prefer to equalize payoffs by lying to avoid the other's payoff exceeding their own $(5,7$ or 
$3,7)$ and they are prone to renounce to equal sharing if lying maximizes their own outcome $(7,3)$. Model (2) also shows that children aged 9-10 are more likely to lie than older children. In addition, model (3) confirms a gender difference in lying behavior when the participant is self-regarding, with girls being less likely to misreport the truth than boys. No specific other-regarding preference effect is observed for females. Model (4) shows the strong influence of self-justification on lying behavior. Finally, the most complete model (5) indicates that the 11 and 14 children are less likely to lie than the two other age categories, except when they can self-justify their behavior after clicking several times on their computer until their favorite allocation option appears on the screen.

We sum up our main findings as follows:

Result 3. Children exhibit a strong lie aversion.

Result 4. Deception follows a hump-shaped profile across age categories. In addition to a lower proneness to lie - even when a lie could increase the recipient's payoff at no personal cost - older children require more selfjustification to lie, compared to younger children.

Result 5. Selfish and envious children are more likely to lie than other-regarding children. Black lies from selfish children are more frequent than white lies from other-regarding children.

Result 6. The gender gap in black lies already exists in childhood: girls are less prone to tell selfish back lies than boys. 


\section{CONCLUSION}

Important developmental changes occur in children between the ages of 7 and 14 . On entering school, social comparisons and interactions with peers become prominent dimensions of a child's development: through aging, children progressively internalize other-regarding preferences. In early adolescence, children become more concerned about efficiency and are more likely to be generous with others. Children progressively base their choices not only on personal gain but also on how their actions will benefit or hurt others. Together with the development of other-regarding preferences, children develop the cognitive ability to lie but also moral reasoning. Although children are taught that lies are morally inappropriate, they may learn that deceit, in some context, can be considered morally acceptable, if lying avoids others being harmed.

We have designed an experiment that allows us to observe both the social preferences of children and their lying behavior. We find that the majority of liars are children who initially expressed selfish preferences and who violated moral rules to satisfy their desire for personal gain or for reasons of envy. The evolution of lying behavior with age follows an inverted U-shaped time path. This results from two forces. First, older children develop stronger social preferences than those in middle childhood and stronger social preferences are associated with a lower likelihood of lying, even when a lie could benefit the partner at no personal monetary cost. Second, older children are more willing to search for a self-serving 
justification when persecuting their self-interest by lying in order to maintain an appearance of honesty in their own eyes. Indeed, as aging, the development of internal evaluative reactions lead children to expect self-disapproval when disregarding their internalized moral standards (Bussey 1999). This type of behavior has been observed in adults (Mazar, Amir and Ariely 2008, Shalvi et al. 2011, Ariely 2012, Fischbacher and Föllmi-Heusi 2013); we provide the first economic paper showing how this type of behavior emerges in children.

Children who hold other-regarding preferences are less prone to lie for two possible reasons. One reason is that when they face the less generous option instead of their preferred option, lying requires more effort than for selfish children. Indeed, it implies not only betraying the moral norm of honesty but also resisting for the second time the temptation of an increased personal payoff. Selfish children who observe the generous option have only to break the ethical norm. The other possible reason is that children learn at the same time the importance of both ethical and social norms. This may explain why efficiency concerned children are less prone to lie than others although their own payoff is kept constant regardless of their reported option.

Overall, we observed a lower propensity to lie in children at all ages compared to most studies on adults. This suggests that the norm of honesty is stronger in children and that most view rules as moral absolutes. Although we guaranteed complete privacy in decision-making, we acknowledge, however, that 
conducting the experiment in schools where respect for rules is important could lead to underestimation of children's propensities to lie, since the environment may influence the decision to behave honestly or not, as showed by Abeler, Becker and Falk (2012). To reconcile the decreasing propensity of lying in children with the higher prevalence of lies in adults, it is suggested that adolescents and young adults learn to develop strategies that allow them to cheat while maintaining their self-image, like using self-deception or moral hypocrisy. The development of self-deception with age in relationship with social preferences would be an interesting extension of this paper.

\section{REFERENCES}

Abeler, Johannes, Anke Becker, Armin Falk. 2012. "Truth-telling - A representative assessment." IZA Discussion Paper 6919.

Almås, Ingvild, Alexander W. Cappelen, Erik Ø. Sørensen, and Bertil Tungodden. 2010. "Fairness and the Development of Inequality Acceptance." Science, 328(5982): 1176-1178.

Ariely, Dan. 2012. The honest truth about dishonesty. HarperCollins.

Benenson, Joyce F., Joanna Pascoe, and Nicola Radmore. 2007. "Children's Altruistic Behavior in the Dictator Game." Evolution and Human Behavior, 28(3): 168-175.

Blake Peter R., and David G. Rand. 2010. "Currency value moderates equity preference among young children." Evolution and Human Behavior, 31: 210218. 
Bricolo, Francesco, Douglas A. Gentile, Rachel L. Smelser and Giovanni Serpelloni. 2007. "Use of the Computer and Internet among Italian families: First national study." Cyberpsychology \& Behavior, 10(6): 789-798.

Broomfield, K. A., E. J. Robinson, and W. P Robinson. 2002. "Children's understanding about white lies." British Journal of Developmental Psychology, 20(1): 47-65.

Bucciol, Alessandro, and Marco Piovesan. 2011. "Luck or cheating? A field experiment on honesty with children." Journal of Economic Psychology, 32(1): 73-78.

Bussey, Kay. 1999. "Children's categorization and evaluation of different types of lies and truths." Child Development, 70(6): 1338-1347.

Bussey, Kay. 1992. "Lying and truthfulness: Children's definitions, standards, and evaluative reactions." Child Development, 63(1): Child Development.

Chandler, Michael, Anna S. Fritz, and Suzanne Hala. 1989. "Small-scale deceit: Deception as a marker of two-, three-, and four-year-olds' early theories of mind." Child Development, 60(6): 1263-1277.

Charness, Gary, and Martin Dufwenberg. 2006. "Promises and Partnership." Econometrica, 74(6): 1579-1601.

Childs, Jason. 2012. "Gender differences in lying." Economics Letters, 114(2): $147-149$.

Dawes, Christopher T., James H. Fowler, Tim Johnson, Richard McElreath, and Oleg Smirnov. 2007. "Egalitarian motives in humans." Nature, 446(7137): 794796.

Dreber, Anna, and Magnus Johannesson. 2008. "Gender differences in deception." 99: 197-199.

Dreber, Anna, Emma von Essen, and Eva Ranehill. 2011. "Outrunning the gender gap_boys and girls compete equally." Experimental Economics 14(4): 567582. 
Erat, Sanjiv, and Uri Gneezy. 2012. "White Lies." Management Science, 58(4): 723-733.

Fehr, Ernst, Helen Bernhard, and Bettina Rockenbach. 2008. "Egalitarianism in young children." Nature, 454(7208): 1079 - 1083.

Fehr, Ernst, and Urs Fischbacher. 2002. "Why social preferences matter - the impact of non-selfish motives on competition, cooperation and incentives." The Economic Journal, 112(478): C1-C33.

Fehr, Ernst, and Urs Fischbacher. 2003. "The nature of human altruism." Nature, 425(6960): 785-791.

Fehr, Ernst, Daniela Glätzle-Rützler, and Matthias Sutter. 2013. "The Development of Egalitarianism, Altruism, Spite and Parochialism in Childhood and Adolescence." European Economic Review, 64: 369-383.

Fischbacher, Urs. 2007. "z-Tree: Zurich Toolbox for Ready-made Economic Experiments." Experimental Economics, 10(2): 171-178.

Fischbacher, Urs, and Franziska Föllmi-Heusi. 2013. "Lies in disguise - An experimental study on cheating." Journal of the European Economic Association, 11(3): 1542-4774.

Gibson, Rajna, Carmen Tanner, and Alexander F. Wagner. 2013. "Preferences for truthfulness: Heterogeneity among and within individuals." American Economic Review, 103(1): 532-548.

Gneezy, Uri. 2005. "Deception: The Role of Consequences." American Economic Review, 95(1): 384-394.

Gneezy, Uri, and Aldo Rustichini. 2004. "Gender and Competition at a Young Age." American Economic Review 94(2): 377-381.

Harbaugh, William T. and Kate Krause. 2000. "Children's altruism in public good and dictator experiments." Economic Inquiry 38(1): 95-109.

Harbaugh, William T., Kate Krause, and Lise Vesterlund. 2002. "Risk Attitudes of Children and Adults: Choices Over Small and Large Probability Gains and 
Losses." Experimental Economics 5(1): 53-84.

Harbaugh, William, Kate Krause, Steve Liday, and Lise Verserlund. 2003. "Trust in children." In Trust, Reciprocity and Gains from Association: Interdisciplinary Lessons from Experimental Research, by Elinore Ostrom and James Walker. New York City: Russell Sage Foundation.

Henrich, Joseph. 2001. "In Search of Homo Economicus: Behavioral Experiments in 15 Small-Scale Societies." American Economic Review, 91(2): 73-78.

Heussner, Ki Mae. 2010. "Biking, Swimming? Nah. Survey Says Kids Master Tech First." abcNEWS, January, 20. http://abcnews.go.com/Technology/bikingswimming-gaming-survey-kids-master-tech-skills/story?id=12657216

Hilbig, Benjamin E., and Ingo Zettler. 2009. "Pillars of cooperation: HonestyHumility, social value orientations, and economic behavior." Journal of Research in Personality, 43(3): 516-519.

Hurkens, Sjaak, and Navin Kartik. 2009. "Would I lie to you? On social preferences and lying aversion." Experimental Economics, 12(2): 180-192.

Kant, Immanuel. 1998. Groundwork of the metaphysics of morals. Translated by Mary J. Gregor. Cambridge: Cambridge University Press.

Lewis, Michael, Catherine Stanger, and Margaret W. Sullivan. 1989. "Deception in 3-Year-Olds." Developmental Psychology, 25(3): 439-443.

López-Pérez, Raúl, and Eli Spiegelman. 2013. "Why do people tell the truth? Experimental evidence for pure lie aversion." Experimental Economics, 16(3): 233-247.

Lundquist, Tobias, Tore Ellingsen, Erik Gribbe, and Magnus Johannesson. 2009. "The Aversion to Lying." Journal of Economic Behavior \& Organization, 70(12): 81-92.

Martinsson, Peter, Katarina Nordblom, Daniela Rützler, and Matthias Sutter. 2011. "Social preferences during childhood and the role of gender and age. An experiment in Austria and Sweden." Economics Letters, 110(3): 248-251. 
Mazar, Nina, On Amir, and Dan Ariely. 2008. "The Dishonesty of Honest People: A Theory of Self-Concept Maintenance." Journal of Marketing Research, 46(6): 633-644.

Nyberg, Sten. 1997. "The honest society: Stability and policy considerations." Journal of Public Economics, 64(1): 83-99.

Ostrom, Elina. 1990. Governing the commons: the evolution of institutions for collective action. Cambridge: Cambridge University Press.

Piaget, Jean. 1965. The moral judgment of the child. New York: The Free Press.

Pruckner, Gerald J., and Rupert Sausgruber. 2013. "Honesty on the Streets: A Field Study on Newspaper Purchasing. " Journal of the European Economic Association, 11(3): 661-679.

Shalvi Shaul, Jason Dana, Michel J.J. Handgraaf, and Carsten K.W. De Dreu. 2011. "Justified ethicality: Observing desired counterfactuals modifies ethical perceptions and behavior." Organizational Behavior and Human Decision Processes, 115:180-191

Sutter, Matthias, and Daniela Rützler. 2010. "Gender differences in competition emerge early in life." Journal of Labor Economics, 8(1): 123-144.

Sutter, Matthias, and Martin G. Kocher. 2007. "Trust and trustworthiness across different age groups." Games and Economic Behavior, 59(2): 364-382.

Sutter, Matthias, Martin G. Kocher, Daniela Glätzle-Rüetzler, and Stefan T. Trautmann. 2013. "Impatience and Uncertainty: Experimental Decisions Predict Adolescents' Field Behavior." American Economic Review 103(1): 510-531.

Talwar, Victoria, and Angela Crossman. 2011. "From little white lies to filthy liars: The evolution of honesty and deception in young children." Advances in Child Development and Behavior, 40: 139-179.

Talwar, Victoria, and Kang Lee. 2008. "Social and Cognitive Correlates of Children's Lying Behavior." Child Development, 79(4): 866-81.

Talwar, Victoria, and Kang Lee. 2002. "Emergence of white lie-telling in children 
between 3 and 7 years of age." Merrill-Palmer Quarterly, 48(2): 160-181.

Talwar, Victoria, Heidi M. Gordon, and Kang Lee. 2007. "Lying in the elementary school: Verbal deception and its relation to second-order belief understanding." Developmental Psychology, 43(3): 804-810.

Talwar, Victoria, Susan M. Murphy, and Kang Lee. 2007. "White lie-telling in children for politeness purposes." International Journal of Behavioral Development, 31(1): 1-11.

Tricomi, Elizabeth, Antonio Rangel, Colin F. Camerer, and John P. O'Doherty. 2010. "Neural evidence for inequality-averse social preferences." Nature, 463(7284): 1089-1091.

Xu, Fen, Xuehua Bao, Genyue Fu, Victoria Talwar, and Kung Lee. 2010. "Lying and truth-telling in children: from concept to action." Child Development, 81(2): 581-596. 


\section{FIGURES AND TABLES}
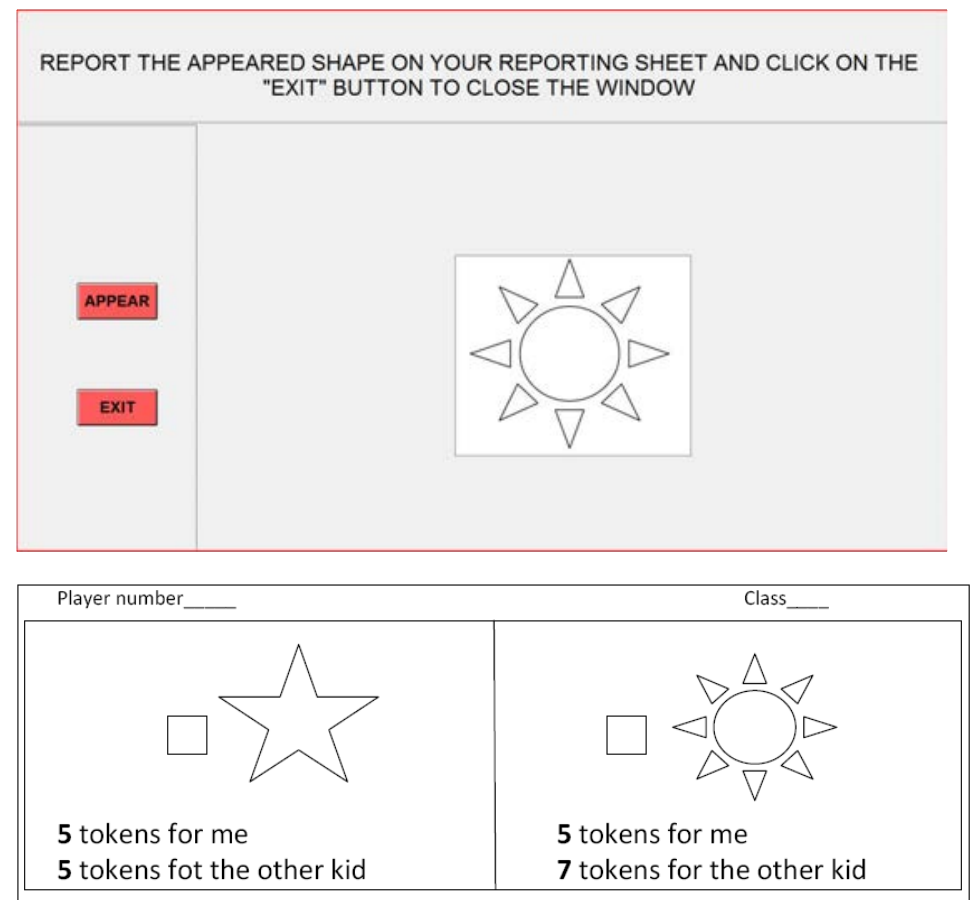

FIGURE 1. SCREENSHOT AND REPORTING SHEET IN STAGE 2

Note: The figure on top displays an example of the screenshot used in the second stage of the experiment. The figure at the bottom represents the reporting sheet that children had to fill out after making a shape appear on their computer screen. 


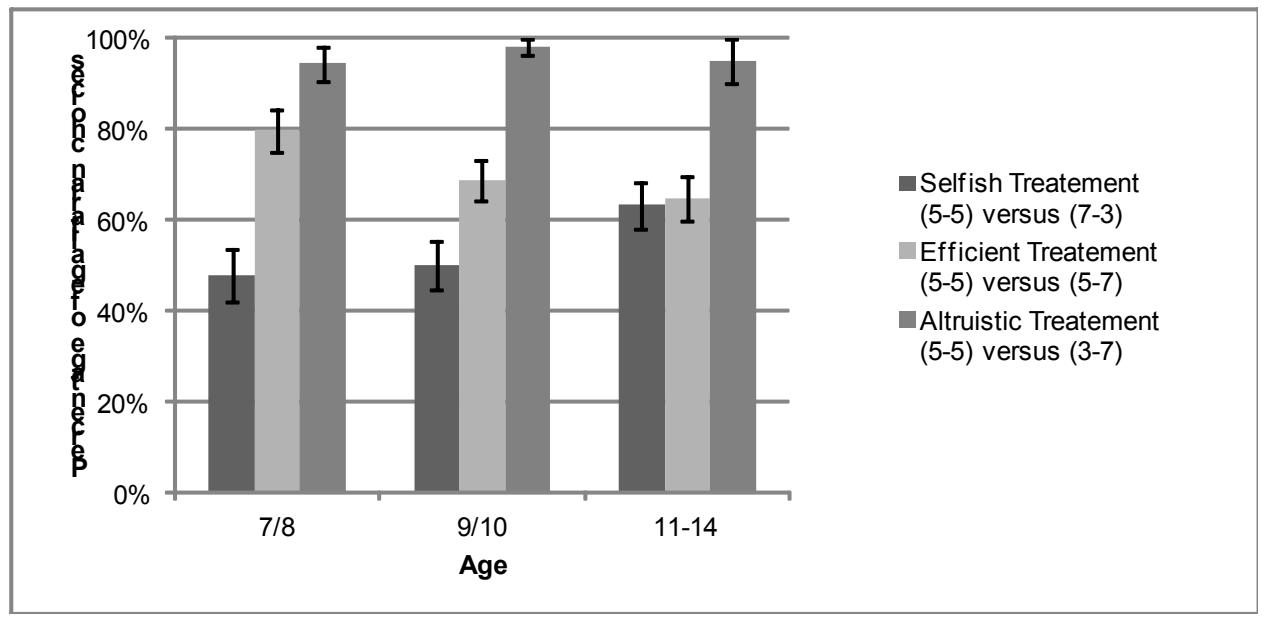

FIGURE 2. FREQUENCY OF EGALITARIAN CHOICES ACROSS AGE GROUPS

Notes: In the Selfishness treatment, the frequency of egalitarian choices increases with age. In the Efficiency treatment, where the alternative option allows children to augment other's payoff at no cost, the 11-14 year olds are more prone to renounce to share points equally. In the Altruism treatment, most children choose the egalitarian allocation independently of age groups. Error bars illustrate standard errors (SEM). 


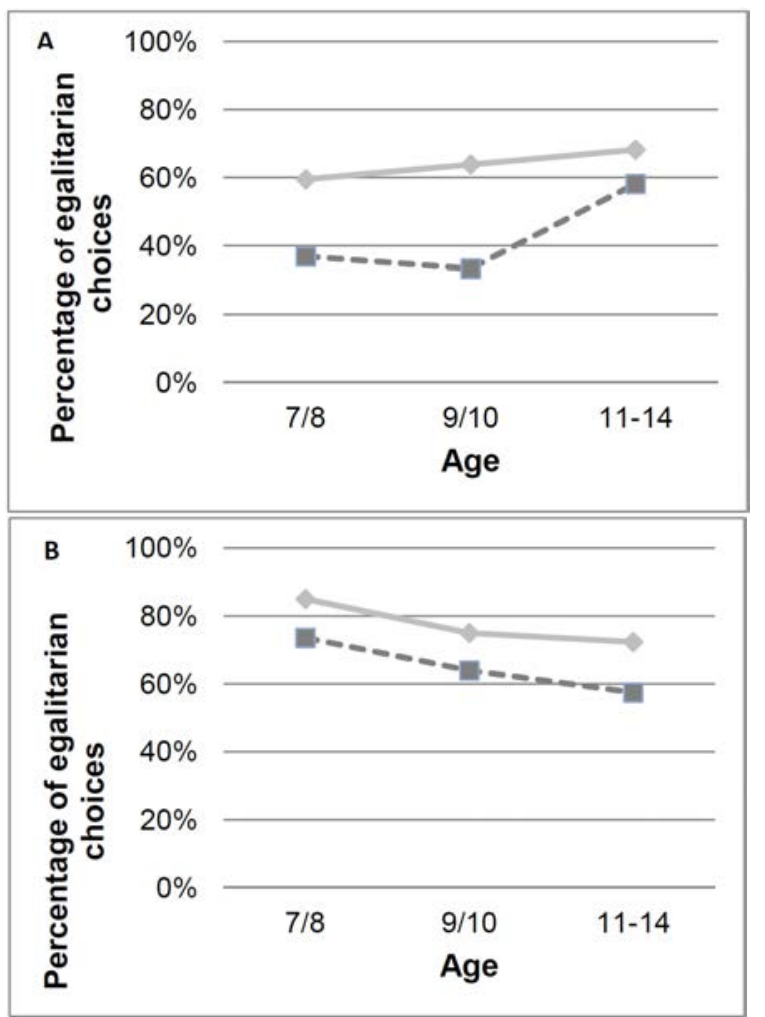

FIGURE 3. GENDER DIFFERENCES IN EGALITARIAN CHOICES

Notes: The solid lines represent the percentages of egalitarian choices of females; the dashed lines represent the corresponding percentages for males. In the Selfishness treatment (A) the choice is between $(5,5)$ and $(7,3)$ whereas in the Efficiency treatment $(B)$ the choice is between $(5,5)$ and $(5,7)$. (A) shows that boys become less selfish as they age; girls are more likely to share equally at all ages but the gap reduces at older ages. (B) shows that both males and females develop a concern for efficiency as they age; the gender gap is small but persistent. 


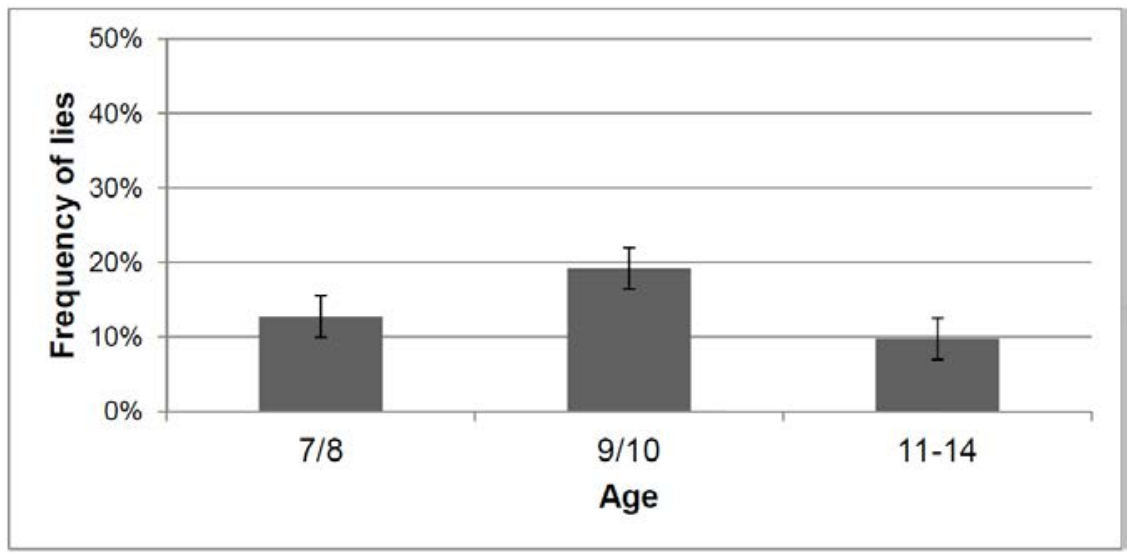

FIGURE 4. FREQUENCY OF LIES ACROSS AGE GROUPS

Notes: The figure shows that the evolution of deceit with respect to age groups is hump-shaped. The 9-10 year old children are more likely to lie than older children. Error bars illustrate standard errors (SEM).

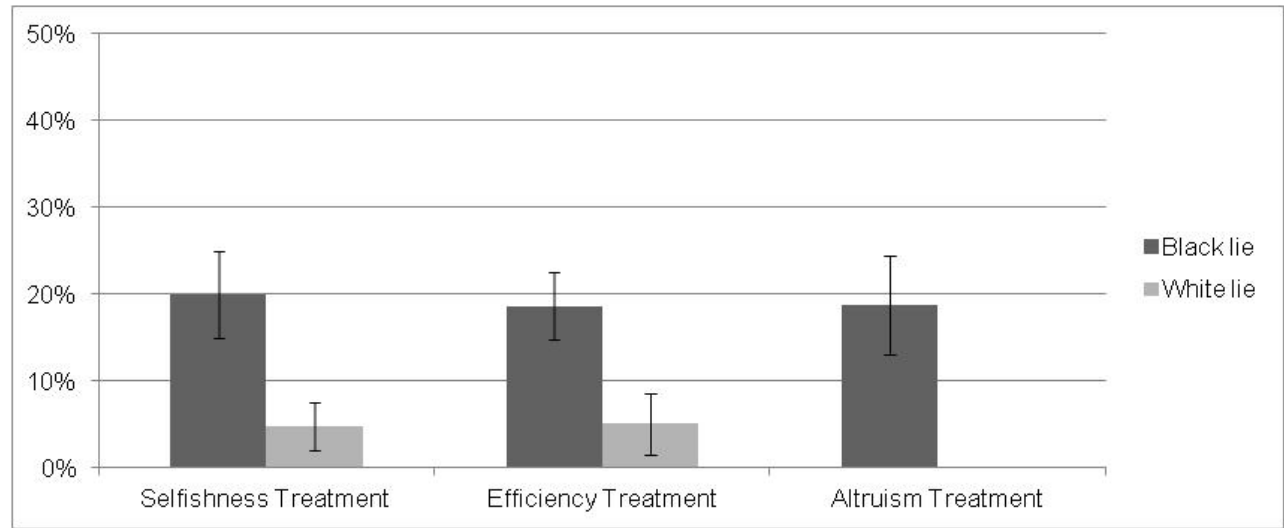

FIGURE 5. LYING BEHAVIOR AND OTHER-REGARDING PREFERENCES

Notes: Black lies decrease the other's payoff while increasing or holding the liar's payoff constant. White lies increase the other's payoff while reducing or holding the liar's payoff constant. When children have to lie to get their preferred allocation option, they are more likely to tell black lies than white lies. This behavior remains constant across all age groups. Error bars illustrate standard errors (SEM). 


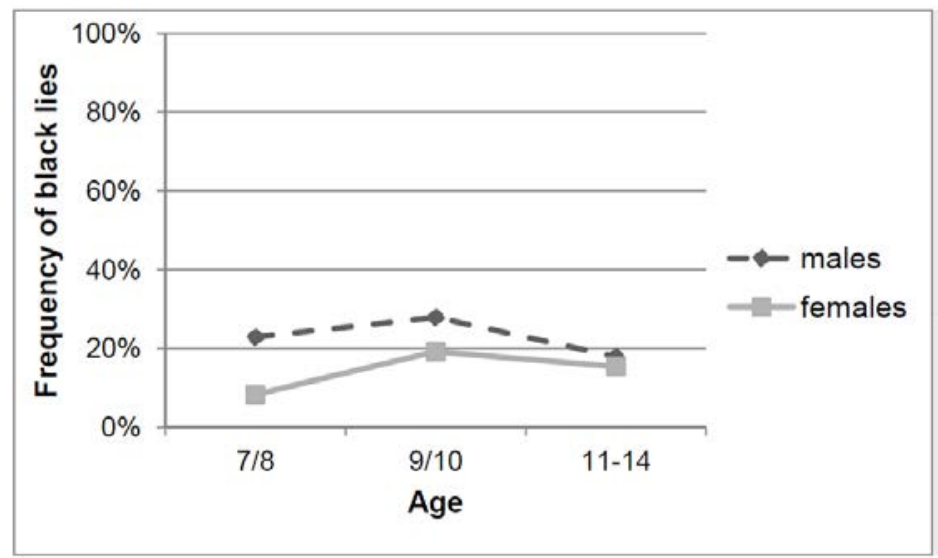

FIGURE 6. LYING GENDER DIFFERENCES IN BLACK LIES

Notes: This figure displays the percentage of children by gender and age group who tell a lie that decreases the other's payoff, among those who did not observe their preferred allocation option in the second part of the experiment. The dashed line is for males; the solid line is for females. Males are more likely to lie than females, but this difference disappears for older children. 
TABLE 1-OTHER-REGARDING PREFERENCES AND CHILDREN'S AGE AND GENDER

\begin{tabular}{|c|c|c|c|c|}
\hline & (1) & (2) & (3) & (4) \\
\hline Selfishness treatment (ST) & $\begin{array}{c}-0.167 * * * \\
(0.042)\end{array}$ & $\begin{array}{l}-0.017 \\
(0.072)\end{array}$ & $\begin{array}{c}-0.205 * * * \\
(0.058)\end{array}$ & $\begin{array}{l}-0.052 \\
(0.083)\end{array}$ \\
\hline $7-8$ year olds & - & $\begin{array}{l}0.162^{* *} \\
(0.072)\end{array}$ & - & $\begin{array}{l}0.159^{* *} \\
(0.072)\end{array}$ \\
\hline $9-10$ year olds & - & $\begin{array}{c}0.050 \\
(0.068)\end{array}$ & - & $\begin{array}{c}0.058 \\
(0.068)\end{array}$ \\
\hline $7-8$ year olds $* \mathrm{ST}$ & - & $\begin{array}{c}-0.324 * * * \\
(0.108)\end{array}$ & - & $\begin{aligned} &-0.323 * * * \\
&(0.109)\end{aligned}$ \\
\hline $9-10$ year olds $*$ ST & - & $\begin{array}{l}-0.183 * \\
(0.104)\end{array}$ & - & $\begin{array}{c}-0.204 * \\
(0.105)\end{array}$ \\
\hline Female & - & - & $\begin{array}{c}0.135 * * \\
(0.060)\end{array}$ & $\begin{array}{l}0.132 * * \\
(0.060)\end{array}$ \\
\hline Female $* \mathrm{ST}$ & - & - & $\begin{array}{c}0.069 \\
(0.083) \\
\end{array}$ & $\begin{array}{c}0.069 \\
(0.083) \\
\end{array}$ \\
\hline \# observations & 525 & 525 & 525 & 525 \\
\hline Log likelihood & -338.485 & -333.827 & -330.563 & -325.879 \\
\hline Pseudo $\mathrm{R}^{2}$ & 0.023 & 0.036 & 0.046 & 0.059 \\
\hline Likelihood-ratio test & 15.7 & 25 & 31.6 & 40.9 \\
\hline$\left(\chi^{2}, p\right.$-value $)$ & $(<0.01)$ & $(<0.01)$ & $(<0.01)$ & $(<0.01)$ \\
\hline $\begin{array}{l}\text { Wald test statistic } \\
\left(\chi^{2}, p \text {-value }\right)\end{array}$ & $\begin{array}{c}15.6 \\
(<0.01)\end{array}$ & $\begin{array}{c}9.2 \\
(<0.05)\end{array}$ & $\begin{array}{c}15.7 \\
(<0.01)\end{array}$ & $\begin{array}{c}15.7 \\
(<0.01)\end{array}$ \\
\hline
\end{tabular}

Notes: This Table presents the marginal effects in Probit regressions. The dependent variable is the EGALITARIAN CHOICE. Standard errors appear in parentheses. $* * *$ indicate significance at the 1 percent level; ** significant at the 5 percent level; * significant at the 10 percent level. 
TABLE 2 - CHILDREN'S LYING BEHAVIOR

\begin{tabular}{|c|c|c|c|c|c|}
\hline & (1) & (2) & (3) & (4) & (5) \\
\hline Other-regarding & - & $-0.137 * * *$ & $-0.179 * * *$ & $-0.152 * * *$ & - \\
\hline preferences & $0.143 * * *$ & $(0.034)$ & $(0.045)$ & $(0.042)$ & $0.148 * * *$ \\
\hline \multirow[t]{2}{*}{$7-8$ year olds } & $(0.034)$ & 0.026 & 0.024 & 0.073 & $(0.041)$ \\
\hline & & $(0.05)$ & $(0.053)$ & $(0.059)$ & $0.137^{*}$ \\
\hline \multirow[t]{2}{*}{$9-10$ year olds } & & $0.082^{*}$ & $0.084^{*}$ & $0.122 * *$ & $(0.077)$ \\
\hline & - & $(0.051)$ & $(0.051)$ & $(0.055)$ & $0.159 * *$ \\
\hline \multirow[t]{2}{*}{ Female } & & - & $-0.070^{*}$ & $-0.068^{*}$ & $(0.068)$ \\
\hline & - & & $(0.041)$ & $(0.038)$ & $-0.063 *$ \\
\hline Female * Other- & & - & 0.156 & 0.122 & $(0.037)$ \\
\hline regarding pref. & - & & $(0.143)$ & $(0.141)$ & 0.113 \\
\hline \multirow[t]{2}{*}{ Justification } & & - & - & $0.565 * * *$ & $(0.140)$ \\
\hline & - & & & $(0.097)$ & $0.767 * * *$ \\
\hline Justification * & & - & - & - & $(0.130)$ \\
\hline 7-8 year olds & - & & & & $-0.094 * *$ \\
\hline Justification * & & & - & - & $(0.020)$ \\
\hline $9-10$ year olds & - & & & & $\begin{array}{l}-0.065 \\
(0.049)\end{array}$ \\
\hline \# observations & 319 & 319 & 319 & 319 & 319 \\
\hline Log likelihood & -124.808 & -123.177 & -121.486 & -99.390 & -97.331 \\
\hline Pseudo $\mathrm{R}^{2}$ & 0.051 & 0.064 & 0.076 & 0.24 & 0.26 \\
\hline Likelihood-ratio & 13.6 & 16.8 & 20.2 & 64.6 & 68.5 \\
\hline$\left(\chi^{2}, p\right.$-value $)$ & $(<0.01)$ & $(<0.01)$ & $(<0.01)$ & $(<0.01)$ & $(<0.01)$ \\
\hline Wald test & 11.6 & 3.24 & 3.35 & 40.7 & 3.99 \\
\hline$\left(\chi^{2}, p\right.$-value $)$ & $(<0.01)$ & $(0.019)$ & $(0.019)$ & $(<0.01)$ & $(0.13)$ \\
\hline
\end{tabular}

Notes: This Table presents the marginal effects in Probit regressions. The dependent variable is THE DECISION TO LIE. Standard errors appear in parentheses. *** indicate significance at the 1 percent level; ** significant at the 5 percent level; * significant at the 10 percent level 


\section{Appendix - Experimental instructions (translated from Italian)}

\section{Introduction}

Hi everybody! How are you? (children answer) My name is Valeria, this is Daniela and this is Giulia. First of all, thanks a lot for letting us come to your school today. It is really nice to be here. Today we are going to play a simple game! Only children whose parents have signed the consent form will participate in the game. If your parents have not signed the consent form, please stay quiet. You are free to not participate in the game if you do not want to, just raise your hand and wait.

\section{Identification}

First of all, you will randomly pick a tag with a random number on it, because it is too difficult for us to remember all your names! Please, attach your number to your shirt. You are not allowed to change your number with others. Please keep this number with you until the end of the game.

Each child picks a number from a bag.

Are you ready? If you do not understand something of this explanation, do not worry: before playing the game I will individually explain to each participant the rules of the game one more time. I will then privately answer all your questions.

\section{Explanations of the rules to the class}

Let's start by explaining the rules of the game. Please pay attention and be quiet! In this game you will have the possibility to earn some tokens that you can exchange at the end of the experiment for pencils, shokkhy-bandz, etc.

An assistant shows the 'prizes' to children (see Figure S5).

As you can see, there are enough pencils, shokky-bandz, etc. for everybody. Obviously, the more tokens you have, the more things you can get.

This game consists of two parts and you will get the tokens you have earned in just one of these two parts: this part will be randomly selected at the very end of the game. Which part to consider in order to give you the tokens DOES NOT DEPEND on the choices you will take, it is completely random.

Now, I am going to explain you the first part of the game: please pay attention and be quiet. If you have any questions I will answer them privately and individually before playing the game.

This game is played in pairs. You are going to be randomly paired with one of your classmates. You will never know which child is your partner in this game.

Remember that you cannot choose your partner, s/he will be chosen at random. 
You will play this game one by one, using a computer. Do not worry, this game is really simple, and if you have any doubts, I will answer all your questions before you play it!

In the first part of the game, you have to make a decision: you have to decide how to divide 10 tokens between yourself and your partner. You will take this decision alone,

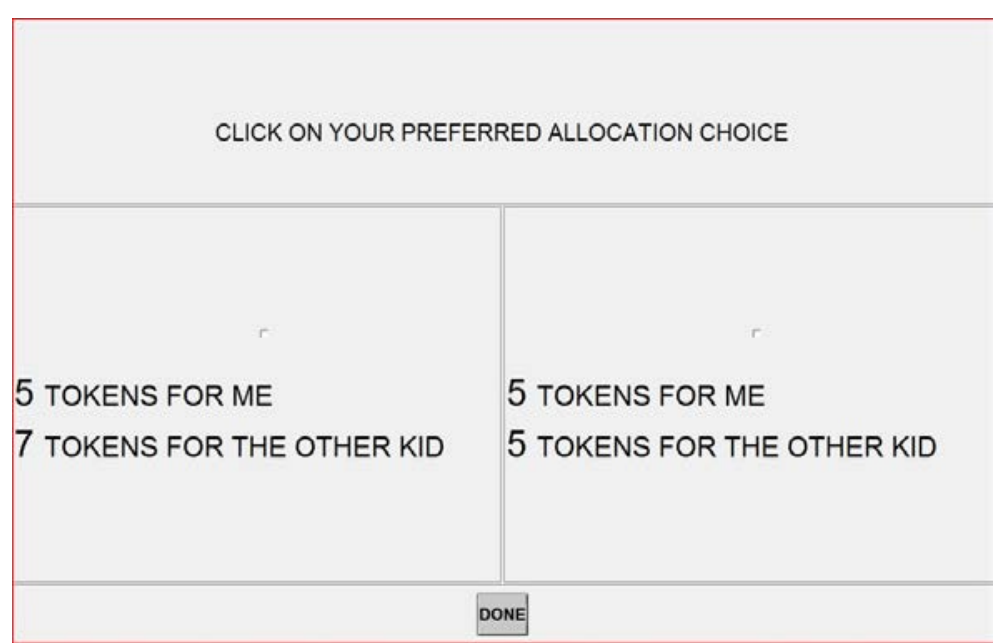

and your parents, your classmates, your teachers will never know what was your choice, not even at the end of the game. One by one, you will leave the classroom, go to another room and make your decision by clicking on the computer screen.

This is what you will see on the computer:

An assistant shows the following poster showing the screenshot for the first part of the game As you can see, there are two possible ways to allocate the tokens between you and the other kid: the option on the left-hand side and the option on the right-hand side. The option on the left-hand side will give to you and to the other kid the same amount of tokens, that is 5 , whereas the right-hand side option will give $5 / 7 / 3$ tokens to you and $7 / 3$ tokens to the other kid. You have to tick the option you prefer by clicking on it. After you have ticked your preferred option, you have to click on the "done" button and wait. Remember that there are no correct or incorrect choices, just choose the option that you prefer.

You will take this decision alone. The other children, the teacher, your friends and your parents will never know what was your choice. Remember that your choice is private, so you are not allowed to speak about it until the very end of the game.

The explanation of the first part of the game is finished... as you have seen, it is a very simple game!

If you have not understood what you have to do, do not worry, before playing the game I am going to individually explain to you the rules of the first part of the game and I will answer all your questions.

Let's start with the second part of the game! Are you ready? Please remember that you are going to get only the tokens you have earned in only one of the two parts of the game: this part will be randomly selected!

After you have clicked on your preferred allocation choice and on the "done" button in the first part of the game, the second part of the game begins. In the second part of the game you will firstly see this screen. 
An assistant shows the following poster showing the screenshot for the second part of the game

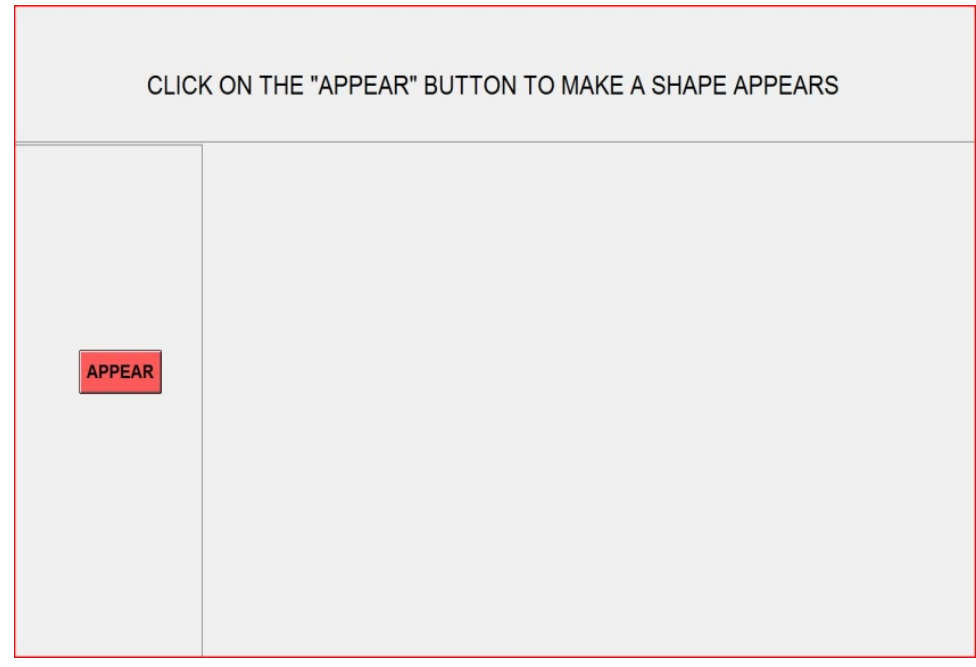

others will see a sun.

An assistant shows the sun and the star to the children.

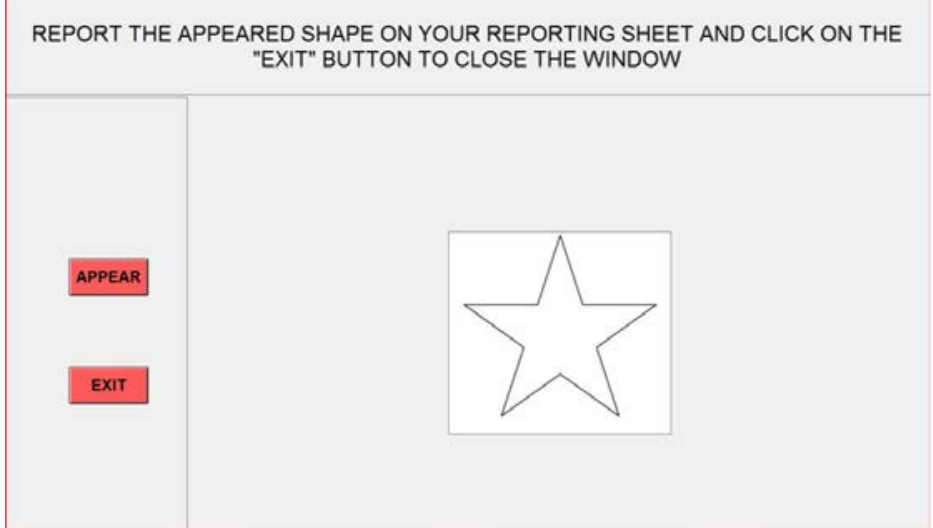

As you can see, this screen asks you to click on the "APPEAR" button in order to make a picture appear. Which picture? A sun or a star! As you click on this "APPEAR" button you will see a sun or a star. In the computer there are as many suns as stars, so you will see one of the two at random. Some of you will see a star, some 


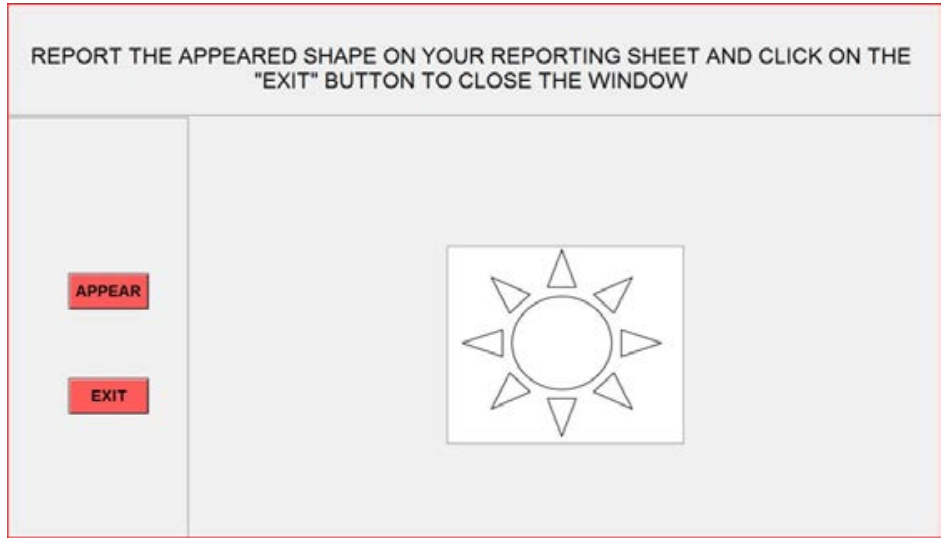

Once you have seen the shape, you have to report which picture you have seen in this reporting sheet.

An assistant shows the reporting sheet to the children.

\begin{tabular}{|l|l|}
\hline Player number__ Class__ \\
$\begin{array}{l}\mathbf{5} \text { tokens for me } \\
\mathbf{5} \text { tokens fot the other kid }\end{array}$ \\
\hline
\end{tabular}

As you can see, this reporting sheet is similar to the computer screen I have just shown you in the first part of the game. The only difference is that you have two pictures: a sun and a star, one for each of the two options.

If you tick that you have seen the star then both you and the other kid will receive 5 tokens, whereas if you tick you have seen the sun then you will receive 5/7/3 tokens and the other kid will receive $7 / 3$ tokens.

After you have ticked one of the two options in the reporting sheet, you have to exit the game by clicking on the "EXIT" button: the "EXIT" button will close the computer screen. Each of you will tick one of the two options alone and the other children, the teacher, your friends and your parents will never know which option you ticked.

Once you have clicked on the exit button the screen will go grey and the game will be finished!

After that, you have to put the reporting sheet in the cardboard box and then come back to your classroom. As in the first part of the game, you are not allowed to speak about it until the very end of the game. 
At the very end of the game, in order to give you the tokens, we will toss this coin in order to select randomly whether we will consider the decisions made in the first part of the game or the reporting sheets you put in the cardboard box in the second part of the game.

As you can see, in these two bags - a white and a black bag - we have all your numbers: numbers in the white bag are paired with numbers in the black bag. Since all of you have participated in the game, at the end of the experiment we will select randomly between one of the two bags and will distribute the tokens according to the choices these children made.

Remember, however, that you will never know the identity of your partner.

If you do not understand what you have to do, don't worry, before playing the game I am going to individually re-explain to you the rules of the first and the second parts of the game and I will answer all your questions.

Let's start with the game! You can come into the room next door, one by one, and play the game with us. Giulia will call out numbers and when you hear your number it's your turn to play. Giulia will take you to me, where you will play the games. When you are finished the games, you can go back to the classroom and carry on drawing. It's really important to us that you do not talk about the game until all the kids have played. We really want you to follow this rule!

\section{Children play the game}

One assistant calls out the next number and fills in name, surname and number of the child on a table. Each odd numbered child is matched with an even numbered child.

\section{Individual explanation of the rules of the game}

Hi! Now I shall explain to you the rules of the game. If you have any questions, please ask me, I shall be happy to answer them all!

In this game you will be paired up with one of the children in your class. You will never know the identity of the other kid, and the other kid will never know your identity, not even at the end of the game. You have to decide how to divide some tokens between yourself and the other kid.

In the first part of the game, you have to choose between two allocation options and you have to click on the one that you prefer. If you tick the left-hand side option, then both you and the other kid will receive 5 tokens; if you tick the right-hand side option then you will receive $7 / 5 / 3$ tokens whereas the other kid will receive $3 / 7$ tokens. Your friends, your teacher, your classmates and your parents will never know what you chose.

Is it clear? Do you have questions? 
After you have clicked on your preferred choice you have to click on the "Done" button. The first part of the game is finished.

In the second part of the game, you have to click on the "Appear" button to make a sun or a star appear. After you have seen the picture, you have to report it on this reporting sheet.

The child is given a reporting sheet, with his/her own number on it.

If you report the sun, then you and the other kid will both receive 5 tokens; if you report the star then you will receive $7 / 5 / 3$ tokens whereas the other kid will receive $3 / 7$ tokens. After you have reported the appeared shape in the reporting sheet, you have to click on the EXIT button to exit the game and close the video screen. Finally, you have to put your reporting sheet in the cardboard box.

Your friends, your teacher, your classmates and your parents will never know which option you ticked.

Remember that you will receive the tokens according to the decisions you make either in the first or in the second part of the game, and this will be random.

Is it clear? Do you have questions?

\section{Distribution of the 'prizes', after all children have played the game}

After all kids have played the game, one assistant tosses a coin to determine whether children will be paid according to the choices made in the first or in the second part of the game. The coin is tossed again to determine whether children will be paid according to the choices made by the children whose number is contained in the white bag or by the children whose number is contained in the black bag.

Now that all the children have played the game, we will tell each of you how many tokens you have won and we will exchange them for what you want, according to this rule:

The following exchange rule is written on the blackboard.

3 tokens: you can get 1 colored pen/pencil or 1 packet of stickers or 5 shokky-bandz.

5 tokens: you can get 2 colored pens/pencils or 2 packets of stickers or 10 shokkybandz. You can also mix the prizes and get 1 pen/pencil and 1 packet of stickers or 1 packet of stickers and 5 shokky-bandz, etc.

7 tokens: you can get 3 colored pens/pencils or 3 packets of stickers or 1 packet of shokky-bandz. You can also mix the prizes and get 1 colored pen/pencil, 5 shokkybandz and 1 packet of stickers or 2 packets of stickers and 5 shokky-bandz, etc.

When I call your number please come here: I will tell you how many tokens you have won so that you can choose the prize you want.

Once you get the prize, please put it in your schoolbag and keep quiet. 


\section{Individual distribution of the prize}

Hi, you have won 3/5/7 tokens! You can get these items, what do you want? Do you like the prize?

\section{End of the experiment}

Thank you very much for participating in this game! We really enjoy our staying! Now you will continue your lesson with Professor xxx. Please, remember not to talk with the others about the game! Bye bye! 
On-line Appendix 1. The decision-making environment

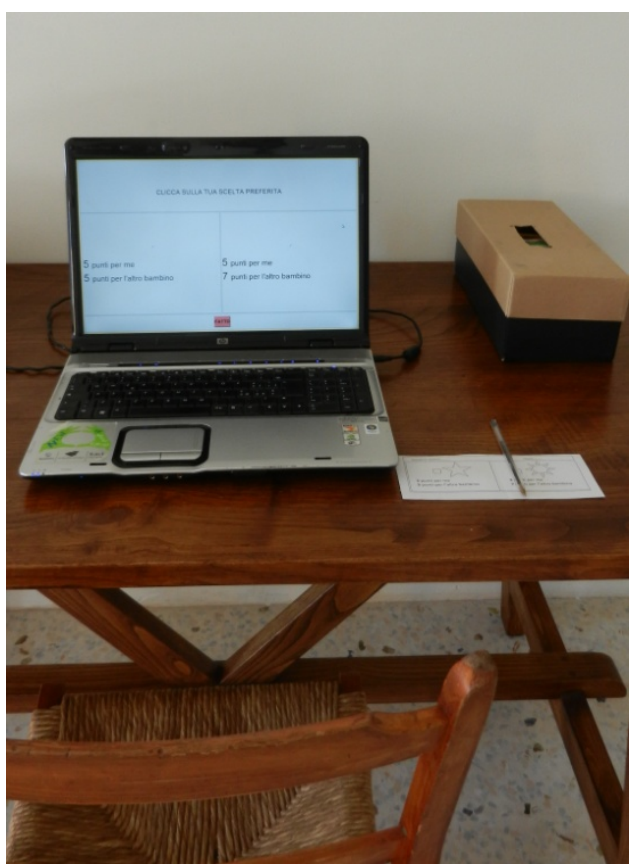

Note: This picture shows the experimental set up in the decision room: a computer, the reporting sheet and the cardboard box. 
On-line Appendix 2. Prizes in the experiment

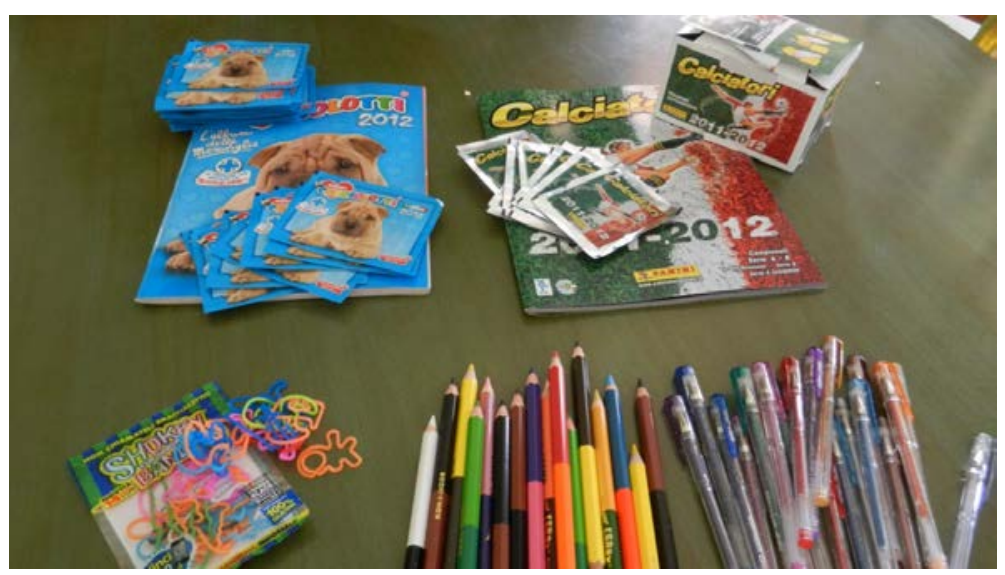

Note: This picture shows the prizes that children could get in exchange for the earned tokens: stickers, colored pens and pencils, "shokky-bandz". 